\title{
Nota Científica / Short Communication Nota taxonômica em Aechmea Ruiz \& Pav. (Bromeliaceae, Bromelioideae) e primeiro registro de Aechmea triangularis L.B.Sm. no estado do Paraná, Brasil ${ }^{1}$
}

Taxonomic note on Aechmea Ruiz \& Pav. (Bromeliaceae, Bromelioideae) and the first record of Aechmea triangularis L.B.Sm. in the Paraná State, Brazil

\author{
Shyguek Nagazak Alves Miyamoto ${ }^{2,4}$ \& Rosângela Capuano Tardivo ${ }^{3}$
}

\begin{abstract}
Resumo
Durante o estudo taxonômico do gênero Aechmea Ruiz \& Pav. no estado do Paraná, Brasil, Aechmea guaratubensis E. Pereira não foi encontrada em campo ou herbários, com exceção do holotypus. Este nome é proposto aqui como nova sinonímia de Aechmea recurvata (Klotzsch) L.B.Sm. Por outro lado, Aechmea triangularis L.B.Sm., conhecida até então como endêmica do estado do Espírito Santo, é registrada pela primeira vez no estado do Paraná.
\end{abstract}

Palavras-chave: Aechmea, distribuição geográfica, taxonomia.

\begin{abstract}
During a taxonomic study of the genus Aechmea Ruiz \& Pav. in the Paraná State, Brazil, Aechmea guaratubensis E. Pereira was not found in fieldworks or in herbarium collections, unless by the holotypus. This name is proposed here as a new synonym of Aechmea recurvata (Klotzsch) L.B.Sm. Moreover, Aechmea triangularis L.B.Sm., known as endemic from Espírito Santo State, is recorded for the first time in the Paraná State. Key words: Aechmea, geographical distribution, taxonomy.
\end{abstract}

\section{Introdução}

Aechmea Ruiz \& Pav. é o maior gênero da subfamília Bromelioideae (Bromeliaceae) com 255 espécies, distribuídas do México ao sul da Argentina, das quais 178 ocorrem no Brasil (Luther 2008; Forzza et al. 2013). Esse gênero é caracterizado morfologicamente por apresentar sépalas, em geral, fortemente assimétricas, com mucros terminais bem desenvolvidos; pétalas sustentando dois apêndices e, muitas vezes, duas calosidades longitudinais; estames inclusos, com anteras dorsifixas; e ovário completamente ínfero, com óvulos geralmente caudados (Ruiz \& Pavón 1797; Smith \& Downs 1979).
Durante a realização de estudos taxonômicos sobre o gênero Aechmea Ruiz \& Pav. no estado Paraná, Brasil, a espécie Aechmea guaratubensis E. Pereira, citada pela literatura como endêmica desse estado, não foi encontrada em campo ou nos herbários visitados, com exceção do holotypus. Essa espécie foi descrita por Edmundo Pereira (1972), com base em um único espécime coletado por Milton Leining em abril de 1972 e depositado no Herbário Bradeanum, Rio de Janeiro. A partir da análise do holotypus e da descrição original, observouse grande proximidade morfológica entre $A$. guaratubensis e Aechmea recurvata (Klotzsch)

\footnotetext{
${ }^{1}$ Parte da dissertação de Mestrado do primeiro autor.

${ }^{2}$ Universidade Estadual de Ponta Grossa/Universidade Estadual do Centro Oeste, Programa de Pós-graduação em Biologia Evolutiva, Av. Carlos Cavalcanti 4748, 84030-900, Ponta Grossa, PR, Brasil.

${ }^{3}$ Universidade Estadual de Ponta Grossa, Depto. Biologia Geral, Programa de Pós-graduação em Biologia Evolutiva, Av. Carlos Cavalcanti 4748, 84030-900, Ponta Grossa, PR, Brasil.

${ }^{4}$ Autor para correspondência: shyguek@gmail.com
} 
L.B.Sm., espécie facilmente reconhecida e abundante no estado.

Por outro lado, Aechmea triangularis L.B.Sm., conhecida até então como endêmica do estado do Espírito Santo, foi registrada pela primeira vez no estado do Paraná. Essa espécie é facilmente reconhecida pelas folhas com margens distintamente aculeadas, com ápices recurvados; escapo e inflorescência densamente albo-flocosos; brácteas do escapo rosadas a avermelhadas, com margens serreadas; inflorescência simples, densiflora e ovoide; brácteas florais avermelhadas; flores com ovário e cálice castanhos, e corola azul. Tais características fazem de $A$. triangularis a espécie mais distinta de Aechmea subg. Macrochordion (de Vriese) Baker (Faria et al. 2010).

Portanto, o objetivo deste trabalho foi realizar uma análise taxonômica comparativa de Aechmea recurvata e $A$. guaratubensis, bem como descrever o primeiro registro de $A$. triangularis para o Paraná.

\section{Material e Métodos}

Este estudo foi baseado nas observações em campo no Paraná, realizadas em expedições de coleta de abril de 2011 a dezembro de 2012, às seguintes regiões fitogeográficas do estado: Floresta Ombrófila Densa, Floresta Ombrófila Mista e Campos Gerais do Paraná (sensu Roderjan et al. 2002). O material coletado foi herborizado seguindo procedimentos descritos por Fidalgo \& Bononi (1989) e depositado no herbário HUPG, da Universidade Estadual de Ponta Grossa. Além disso, foram analisadas exsicatas depositadas nas coleções dos herbários BR, EFC, FUEL, GH, HB, HBR, HUPG, MBM, SP e UPCB (acrônimos segundo Thiers, continuously updated), dentre as quais, materiais-tipo de Aechmea recurvata (foto $\mathrm{BR})$, A. guaratubensis (HB) e A. triangularis (foto $\mathrm{GH}$ ). Ainda, foram analisadas as descrições originais dos táxons aqui tratados e consultada a literatura especializada.

A terminologia utilizada nas descrições segue Radford et al. (1974) e Gonçalves \& Lorenzi (2011). A descrição de Aechmea recurvata foi baseada na análise do holotypus de $A$. recurvata var. benratti (Mez) Reitz, do material coletado e das descrições nas obras de Smith \& Downs (1979), Reitz (1983) e Wanderley $\&$ Martins (2007). Os dados morfológicos de $A$. guaratubensis foram obtidos a partir da análise do holotypus e da descrição original. Os espécimes de $A$. triangularis coletados no Paraná foram identificados em comparação com o holotypus, com a descrição original (Smith 1955) e com a descrição e chave de identificação presentes no trabalho de Faria et al. (2010). A descrição de $A$. triangularis foi baseada no material coletado no Paraná. A indicação do estado de conservação dessa espécie, no Paraná, seguiu critérios da IUCN $(2001 ;$ 2012). O mapa de distribuição foi elaborado utilizando os programas Quantum Gis 1.8 e Corel Draw 15.0, a partir das coordenadas das localidades do material examinado.

\section{Resultados}

1. Aechmea recurvata (Klotzsch) L.B.Smith, Contr. Gray Herb. 98: 5. 1932. Typus: Blass Hortus, s/ data, s/n (Holotypus B). Aechmea guaratubensis E.Pereira, Bradea 1(25): 278. 1972. Typus: BRASIL. PARANÁ: Guaratuba, 20.IV.1972, M. Leining 506 (Holotypus HB!), syn. nov. Fig. 1a-d Epífita ou rupícola, raramente terrícola. Planta florida 7,5-27 cm de alt. Rizoma ca. 11 $\times 0,7-1,5 \mathrm{~cm}$. Folhas $15-35$, raramente menos, 13-70 cm compr., raramente até $115 \mathrm{~cm}$ compr., recurvadas, coriáceas, formando uma roseta pseudo-utriculada; bainhas 2,4-11 × 1-6,5 cm, estreito-ovadas a ovadas, margens inteiras, verdearroxeadas; lâminas 7,5-62 × 0,5-3 cm larg. na base, lineares a estreito-triangulares, verdes nas folhas externas e geralmente vermelhas nas internas durante a floração, face abaxial lepidota com nervuras evidentes e face adaxial lisa e glabrescente, margens com acúleos de 1-2 $\mathrm{mm}$, ápice atenuado e pungente. Escapo 4-18 × $0,6-1,4 \mathrm{~cm}$, incluso na roseta foliar, alvo, glabro; brácteas do escapo geralmente 5 , imbricadas, $5,5-9 \times$ ca. 1,5 cm, largo-ovadas a triangulares, papiráceas, alvas na base e avermelhadas no ápice, margens serrilhadas, ápice atenuado e pungente. Inflorescência corimbiforme a obovoide, 3,7-6,8 x 4-7,2 cm; raque completamente encoberta pelas flores; brácteas florais $2-5,2 \times 0,8-2,3$ $\mathrm{cm}$, ovadas a lanceoladas, papiráceas, alvas na base e avermelhadas no ápice, margens inteiras a serreadas próximo ao ápice, ápice agudo a atenuado. Flores sésseis, polísticas, 2,7-5,1 cm compr.; sépalas $1-1,5 \times 4-5 \mathrm{~mm}$, incluindo mucro terminal de $2-3 \mathrm{~mm}$, conatas por $3-5 \mathrm{~mm}$ 
na base, assimétricas, alvas na base e vermelhas no ápice, ápice arredondado, albo-lepidotas; pétalas $1,5-2,5 \times$ ca. $6 \mathrm{~mm}$, espatuladas, com 2 calosidades longitudinais e 2 apêndices longofimbriados suprabasais, alvas na base e rosas a roxas no ápice, ápice emarginado e cuculado; estames 1,4-2,3 cm compr.; filetes achatados dorso-ventralmente; anteras $4-5 \mathrm{~mm}$ compr., elípticas, amarelas; ovário 1,5-2 × ca. $7 \mathrm{~mm}$, trígono, levemente sulcado, alvo, glabro; óvulos obtusos, não caudados, dispostos na porção mediano-superior do ovário; estilete 1,3-2,3 cm compr.; estigma espiral-conduplicado. Fruto baga, com sépalas persistentes, ca. 3,5 $\times 1 \mathrm{~cm}$, obovoide, glabro, negro. Sementes ca. $2,5 \mathrm{~mm}$ compr., cuneiformes, coloração castanha.

Material examinado: BRASIL. PARANÁ: Antonina, Serrinha, 22.IV.1994, fl., G. Hatschbach 60656 (MBM). Araucária, Guajuvira, 31.VIII.2001, fr., R.A. Kersten et al. 533 (EFC). Bituruna, Salto Grande do Rio Iguaçú, 17.X.1966, fl., G. Hatschbach 14952 (MBM). Carambeí, Faz São Daniel, 20.IV.2011, fl., S.N.A. Miyamoto et al. 3 (HUPG). Castro, Rio Pitangui, 5.IV.2012, fr., S.N.A. Miyamoto \& V.K. Kowalski 137 (HUPG). Cerro Azul, P.E. de Campinhos, 30.III.2012, fr., S.N.A. Miyamoto et al. 134 (HUPG). Colombo, fr., P.R. de Andrade (MBM 298567). Curitiba, Parque Barigui, 25.I.1996, fl., C. Kozera et al. 58 (UPCB). Guaíra, Parque Nacional Sete Quedas, 6.I.1986, fl., E. Buttura 1002 (MBM). Guaraqueçaba, Rio do Cedro, 11.IV.1968, fl., G. Hatschbach 19012 (MBM). Horizonte, BR 280, 28.I.1985, fr., A. Krapovickas \& C.L. Cristóbal 39737 (MBM). Ipiranga, Rio Bitumirim, 27.VIII.1975, fl., G. Hatschbach 37030 (MBM). Irati, Col. Estância Florida, 30.XI.1972, fl., P. Carvalho 128 (MBM). Jataizinho, Sítio Sumya, 23.VIII.1998, fr., A.F.L. Vanzela et al. (FUEL 29514). Lapa, Santo Amaro, 16.III.1967, fl., G. Hatschbach 16171 (MBM). Laranjeiras do Sul, Serra da União, 12.X.1962, fl., G. Hatschbach 9397 (MBM). Mangueirinha, PR 449, 19.IX.2001, f1., G. Hatschbach et al. 72376 (MBM). Morretes, 1.IX.1939, fr., M. Kuhlmann (SP 41609). Palmas, Refúgio da Vida Silvestre, 28.I.2012, fr., S.N.A. Miyamoto \& A.C. de Azevedo 107 (HUPG). Palotina, Rio azul, 28.VI.1966, fl., J. Lindeman \& H. Haas 1797 (MBM). Pinhão, 10.IX.1996, fl., A.C. Slovenski \& J.S. Muniz 187 (EFC). Piraquara, 21.V.1968, fl., N. Imaguire 2087 (MBM). Ponta Grossa, P.E. de Vila Velha, 29.IX.2011, fr., S.N.A. Miyamoto et al. 31 (HUPG). Prudentópolis, Salto Manduri, 8.II.2012, S.N.A. Miyamoto \& V.K. Kowalski 113 (HUPG). Reserva, 6.III.1967, fr., J. Lindeman \& H. Haas 4661 (MBM). Rio Bonito do Iguaçú, Pinhal
Ralo, 23.VI.1995, fl., C.B. Poliquesi \& J. Cordeiro 330 (MBM). São Mateus do Sul, Faz. do Durgo, 16.IX.1986, fl., S.M. Silva \& R.M. Britez 716 (MBM). Tibagi, P. E. do Guartelá, 9.VII.2011, fl., S.N.A. Miyamoto \& M. Engels 14 (HUPG). Três Barras do Paraná, 2.IX.1999, fl., J.M. Silva et al. 3055 (MBM).

Aechmea recurvata é facilmente reconhecida por apresentar roseta pseudo-utriculada, folhas centrais geralmente vermelhas durante a época de floração, escapo curto e encoberto pela roseta, inflorescência corimbiforme, brácteas florais com nervuras evidentes, muitas vezes com margens serreadas, flores geralmente excedendo $3 \mathrm{~cm}$ compr., pétalas rosas a roxas e ovário glabro e subtrígono (Smith \& Downs 1979; Reitz 1983; Wanderley \& Martins 2007).

Aechmea recurvata apresenta quatro táxons infraespecíficos. Aechmea recurvata var. recurvata é caracterizada pela inflorescência completamente exserta, acima das bainhas foliares, e brácteas florais avermelhadas com margens serreadas. As demais variedades caracterizam-se pela inflorescência quase ou completamente inclusa nas bainhas foliares e são diferenciadas pelas brácteas florais: avermelhadas com margens fortemente serreadas em $A$. recurvata var. ortgiesii (Baker) Reitz, avermelhadas com margens inteiras em $A$. recurvata var. benrathii (Mez) Reitz e brancas com margens serreadas em $A$. recurvata var. albobracteata Strehl. As duas primeiras variedades possuem distribuição relativamente ampla, incluindo o Paraná. As duas últimas variedades são endêmicas de Santa Catarina e do Rio Grande do Sul, respectivamente (Reitz 1983; Forzza et al. 2013).

Após a análise do holotypus de Aechmea guaratubensis, observou-se que tal espécime é um exemplar de $A$. recurvata var. ortgiesii, táxon comum nesse estado. A localidade exata de coleta do holotypus de A. guaratubensis é incerta, mas sabe-se que foi coletado no município de Guaratuba. No entanto, nenhum exemplar de $A$. recurvata foi encontrado durante as expedições realizadas à Guaratuba, bem como não há material herborizado dessa espécie referente a tal município. Além disso, como pode ser observado na Tabela 1 e na Figura 1, não há diferenças morfológicas que sustentem a manutenção da espécie $A$. guaratubensis, sendo esse táxon aqui proposto como nova sinonímia de $A$. recurvata. 

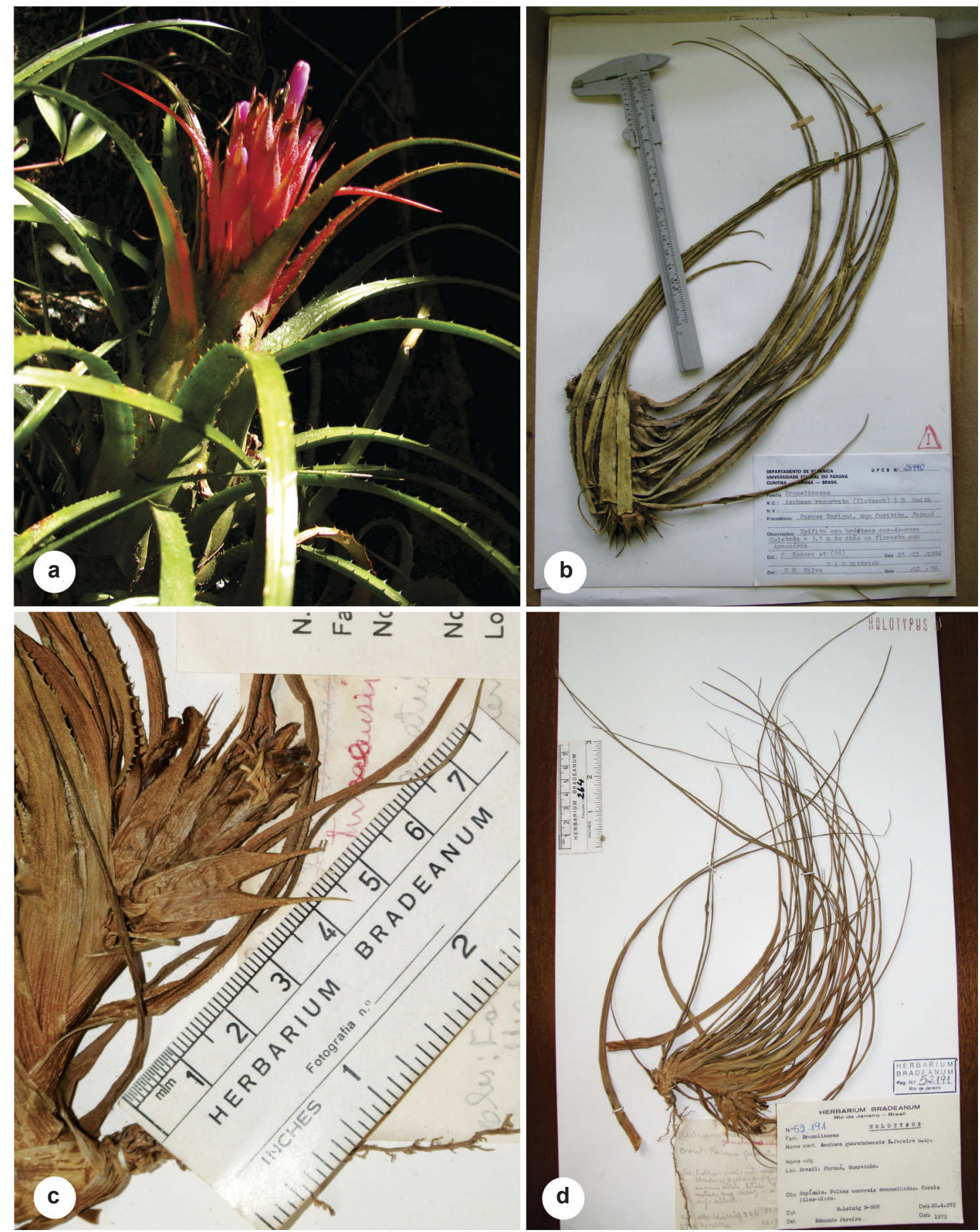

Figura 1 - a-b. Aechmea recurvata - a. espécime coletado no Parque Estadual do Guartelá, Tibagi (S.N.A. Miyamoto \& M. Engels 14, HUPG); b. (C. Kozera et al. 58, UPCB). c-d. Holotypus de A. guaratubensis (M. Leining 506, HB). Figure 1 - a-b. Aechmea recurvata. a: specimen collected in the Parque Estadual do Guartelá, Tibagi (S.N.A. Miyamoto \& M. Engels 14, HUPG); b. (C. Kozera et al. 58, UPCB). c-d. Holotypus of A. guaratubensis (M. Leining 506, HB). 
Tabela 1 - Descrição do hábito e comparação morfológica entre Aechmea recurvata e A. guaratubensis.

Table 1 - Habit description and morphological comparison between Aechmea recurvata and A. guaratubensis.

\begin{tabular}{|c|c|c|}
\hline Característica & Aechmea recurvata & Aechmea guaratubensis \\
\hline Hábito & Epífita, rupícola, raramente terrícola & Rupícola \\
\hline Altura da planta & $7,5-27 \mathrm{~cm}$ & $11 \mathrm{~cm}^{*}\left(40 \mathrm{~cm}^{* *}\right)$ \\
\hline Roseta & Pseudo-utriculada & Pseudo-utriculada \\
\hline Folhas & $\begin{array}{l}15-35 \text {, denso rosuladas, as internas menores e } \\
\text { vermelhas durante a floração }\end{array}$ & $\begin{array}{l}35 \text {, denso-rosuladas, as internas menores e } \\
\text { vermelhas durante a floração }\end{array}$ \\
\hline Folhas: lâmina & $\begin{array}{l}7,5-62 \times 0,5-3 \mathrm{~cm} \text {, albo-lepidota na face } \\
\text { abaxial e glabrescente na adaxial, margens } \\
\text { com acúleos de } 1-2 \mathrm{~mm}\end{array}$ & $\begin{array}{l}12-40 \times 0,5-0,8 \mathrm{~cm} \text {, albo-lepidota na face } \\
\text { abaxial e glabra na adaxial, margens com } \\
\text { acúleos até ca. } 1 \mathrm{~mm} *\left(0,5 \mathrm{~mm}^{* *}\right)\end{array}$ \\
\hline Folhas: bainha & $2,4-11 \times 1-6,5 \mathrm{~cm}$, estreito-ovadas a ovadas & $4-5 \times 1,5 \mathrm{~cm}$, largo-triangulares \\
\hline Escapo & Incluso na roseta foliar & Incluso na roseta-foliar \\
\hline Inflorescência & Simples, corimbiforme a obovoide & $\begin{array}{l}\text { Simples, corimbiforme* (compacto- } \\
\text { elipsoidea**) }\end{array}$ \\
\hline Brácteas florais & $\begin{array}{l}2-5,2 \times 0,8-2,3 \mathrm{~cm} \text {, largo-ovadas a } \\
\text { lanceoladas, plurinervadas, margens inteiras } \\
\text { ou serreadas, avermelhadas no ápice e alvas } \\
\text { na base, albo-lepidotas }\end{array}$ & $\begin{array}{l}3,5-4 \times \text { ca. } 1,5 \mathrm{~cm} \text {, ovado-lanceoladas, } \\
\text { plurinervadas, margens serreadas, purpúreas, } \\
\text { albo-lepidotas }\end{array}$ \\
\hline Flores & 2,7-5,1 cm compr., sésseis & ca. $3,5 \mathrm{~cm}$ compr., sésseis \\
\hline Sépalas & $\begin{array}{l}0,7-1,5 \mathrm{~cm} \text { compr., mais mucro terminal } \\
\text { de } 2-3 \mathrm{~mm} \text {, conatas por } 3-5 \mathrm{~mm} \text { na } \\
\text { base, assimétricas, albo-lepidotas, ápice } \\
\text { arredondado }\end{array}$ & $\begin{array}{l}\text { ca. } 1 \mathrm{~cm} *\left(6 \mathrm{~mm}^{* *}\right) \text { compr., mais mucro } \\
\text { terminal de } 1,5 \mathrm{~mm} \text {, conatas por } 3 \mathrm{~mm} \text { na base, } \\
\text { assimétricas, albo-lepidotas, ápice arredondado }\end{array}$ \\
\hline Pétalas & $\begin{array}{l}\text { 1,5-2,5 cm compr., espatuladas, com um } \\
\text { par de apêndices fimbriados na base, ápice } \\
\text { arredondado e emarginado, alvas na base e } \\
\text { rosas a roxas no ápice }\end{array}$ & $\begin{array}{l}2 \mathrm{~cm} \text { compr., espatuladas, com um par } \\
\text { de apêndices fimbriados na base, ápice } \\
\text { arredondado e emarginado, alvas na base a } \\
\text { lilases no ápice }\end{array}$ \\
\hline Estames & Inclusos, dispostos em duas séries & Inclusos, dispostos em duas séries \\
\hline Anteras & $\begin{array}{l}\text { Elípticas, pouco curvadas, } 4-5 \mathrm{~mm} \text { compr., } \\
\text { dorsifixas }\end{array}$ & $\begin{array}{l}\text { Elípticas* (lineares**), pouco curvadas, com } 5 \\
\text { mm* }\left(6 \mathrm{~mm}^{* *}\right) \text { compr., dorsifixas }\end{array}$ \\
\hline Ovário & 1,5-2 cm compr., subtrígono, alvo, glabro & 1,4 cm compr., subtrígono, alvo, glabro, \\
\hline Óvulos & $\begin{array}{l}\text { Obtusos, dispostos na porção mediano-superior } \\
\text { do ovário }\end{array}$ & $\begin{array}{l}\text { Obtusos, dispostos na porção mediano-superior } \\
\text { do ovário }\end{array}$ \\
\hline
\end{tabular}

$(*)$ observado no holotypus; $(* *)$ descrição original.

2. Aechmea triangularis L.B.Sm., Smithsonian Misc. Collect. 126(1): 19, 224, fig. 106. 1955. Typus: BRASIL. ESPÍRITO SANTO: Santa Teresa, 7.VIII.1940, Foster 829 (Holotypus GH!).

Fig. 2a-c

Epífita. Planta florida $57-62 \mathrm{~cm}$ alt. Rizoma ca. $6 \times 2,5 \mathrm{~cm}$. Folhas $13-18,42-70 \mathrm{~cm}$ compr., cartáceas, lepidotas, formando uma roseta tubulosa; bainhas $12-19 \times 7-10 \mathrm{~cm}$, ovadas, margens inteiras, verdes; lâminas 23-68 × 3-7 cm, lineartriangulares, verdes, margens com acúleos negros 2-7 mm, ápice agudo a acuminado, recurvado.
Escapo 43-49 × 0,7-1 cm, castanho esverdeado, densamente albo-flocoso; brácteas do escapo ca. 12 , 5,5-11 × 1,4-2,7 cm, lanceoladas a estreito-ovadas, margens serreadas, ápice acuminado, papiráceas, levemente rosadas, lepidotas. Inflorescência estrobiliforme, 4,5-7 × 3,3-3,8 cm, densamente albo-flocosa, exceto pelas pétalas; brácteas florais amplexifloras, adnatas a raque, $5-8 \mathrm{~mm} \times 1,8 \mathrm{~cm}$, carenada, ápice truncado e apiculado, coriáceas, vináceas. Flores 60-75, sésseis, polísticas, 1,5-1,7 cm compr.; sépalas ca. $6 \times 4 \mathrm{~mm}$, conatas por ca. $3 \mathrm{~mm}$ na base, assimétricas, verdes com margens 

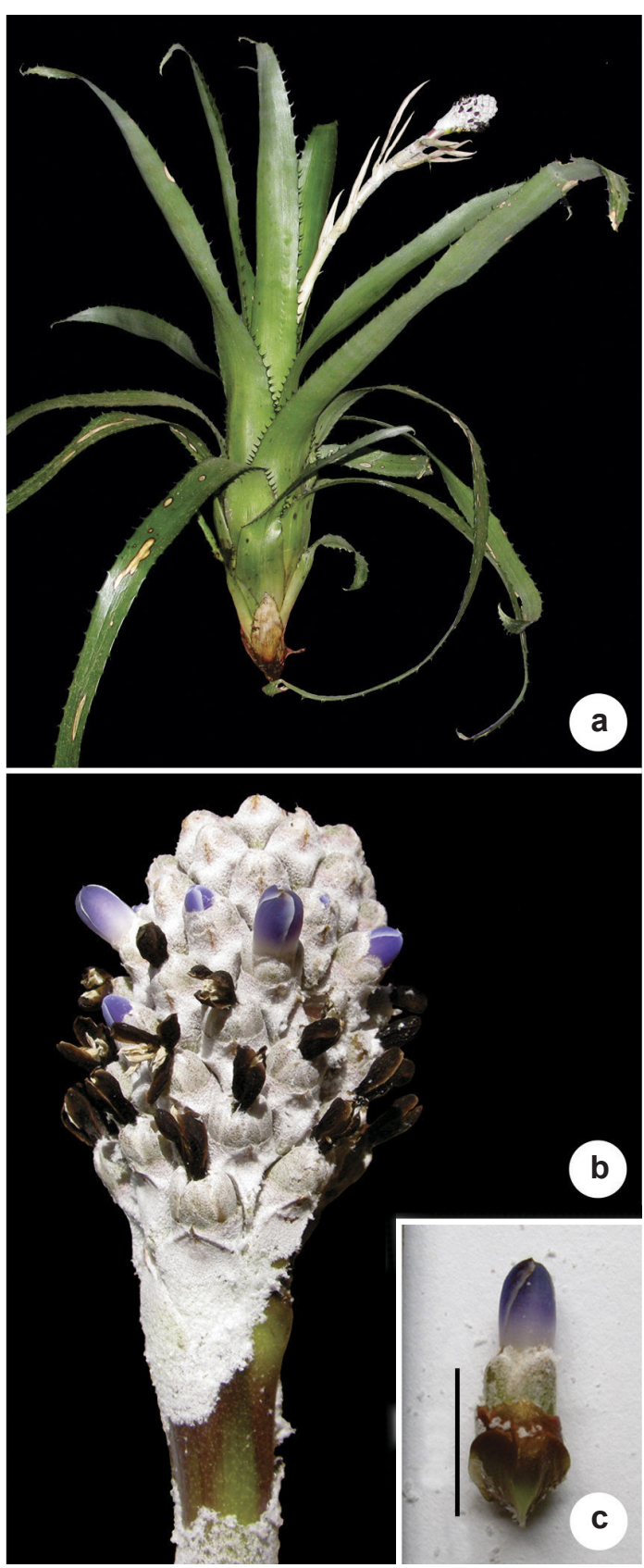

Figura 2 - a-c. Aechmea triangularis - a. planta florida; b. inflorescência em detalhe; c. flor em detalhe (S.N.A. Miyamoto 151, HUPG).

Figure 2 - a-c. Aechmea triangularis - a. flowering plant; b. inflorescence in detail; c. flower in detail (S.N.A. Miyamoto 151, HUPG).

e ápice castanhos, ápice emarginado e apiculado; pétalas ca. $1,2 \times 4 \mathrm{~mm}$, com 2 apêndices fimbriados suprabasais e 2 tênues calosidades longitudinais, ápice retuso, alvas na base a azuis no ápice, tornando-se negras após a antese; estames 1,2-1,4 $\mathrm{cm}$, alvos, anteras ca. $3,5 \mathrm{~mm}$ compr., elípticas, albo-amareladas; ovário ca. $4 \times 4 \mathrm{~mm}$; óvulos longo-caudados dispostos na porção superior do ovário; estilete ca. $1 \mathrm{~cm}$ compr., filiforme, alvo; estigma espiral-conduplicado, alvo. Frutos e sementes não vistos.

Material examinado: BRASIL. PARANÁ: Carambeí, Catanduva de Fora, 8.IX.2011, fl., M.E. Engels 288 (HUPG). Ponta Grossa, Cachoeira da Mariquinha, 3.X.2012, fl., S.N.A. Miyamoto 151 (HUPG).

Material adicional examinado: BRASIL. ESPÍRITO SANTO: Santa Teresa, 7.VIII.1940, fl., Foster 829 (Holotypus, foto $\mathrm{GH}$ ).

Aechmea triangularis pode ser facilmente reconhecida, destacando-se dentre as demais espécies de Aechmea subg. Macrochordion principalmente por ser a única espécie a apresentar corola azul.

Aechmea triangularis tem sido considerada endêmica do estado do Espírito Santo, onde ocorre como epífita, em áreas de Floresta Ombrófila Densa Montana, em altitudes entre 650-1000 m (Faria et al. 2010; Forzza et al. 2013). Contudo, foram encontradas duas populações dessa espécie na Região Centro Oriental do estado do Paraná, sendo este o primeiro registro da espécie nesse estado. Uma população está localizada em Catanduva de Fora (245 $\left.57^{\prime} 44^{\prime \prime} \mathrm{S}-50^{\circ} 01^{\prime} 26^{\prime \prime} \mathrm{W}\right)$, município de Carambeí, e outra nos arredores da Cachoeira da

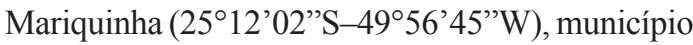
de Ponta Grossa (Fig. 3). Essas populações são formadas por indivíduos epífitos, em sub-bosque de Floresta Ombrófila Mista (Floresta com Araucária), em altitudes próximas a $1000 \mathrm{~m}$. As causas da distribuição disjunta dessa espécie ainda não foram esclarecidas.

Faria et al. (2010) afirmaram que Aechmea triangularis está em perigo de extinção no estado do Espírito Santo, onde apresenta distribuição geográfica restrita e é pouco representada em coleções herborizadas. No Paraná, seguindo critérios estabelecidos pela IUCN $(2001,2012)$, a espécie está criticamente em perigo de extinção (CR: $\mathrm{B} 1 \mathrm{~B} 2 \mathrm{ab}[\mathrm{iii}] \mathrm{D})$, com populações pequenas, isoladas, com extensão de ocorrência estimada em cerca de $70 \mathrm{~km}^{2}$ e área de ocupação em apenas $24 \mathrm{~km}^{2}$. Além disso, ambas as populações do Paraná estão ameaçadas pela ação antrópica, sofrendo provável declínio contínuo, sendo aquela de Catanduva de Fora (Carambeí) vítima de desmatamento e a da Cachoeira da Mariquinha (Ponta Grossa) sujeita a ação de intensa atividade turística sem normativas 


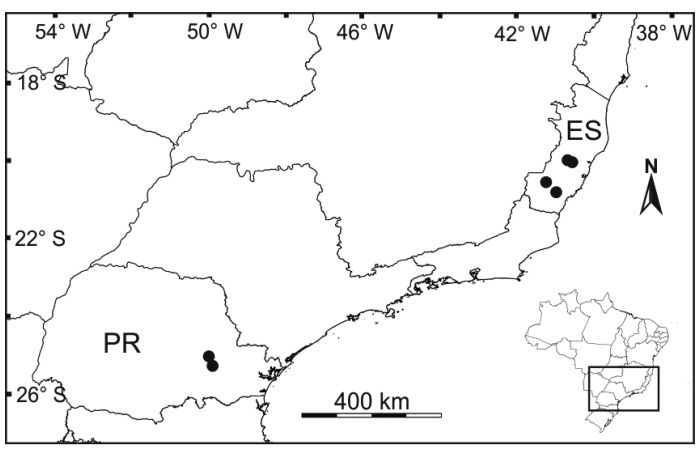

Figura 3 - Localização das populações de Aechmea triangularis nos estados do Espírito Santo (ES) e Paraná (PR).

Figure 3-Location of Aechmea triangularis populations in the Espírito Santo State (ES) and Paraná State (PR).

de controle de danos ambientais, apesar de se encontrar dentro do Parque Nacional dos Campos Gerais, ainda em implementação.

\section{Agradecimentos}

Os autores agradecem aos curadores e técnicos dos herbários citados. Ao IAP pela autorização de pesquisa e coleta nas unidades de conservação do Paraná ( $\left.{ }^{\circ} 308 / 11\right)$. Ao CNPq pela concessão da bolsa de mestrado do primeiro autor (Processo 159723/2010-8) e pelo apoio financeiro ao projeto: PROTAX - Estudos taxonômicos com Monocotiledôneas no estado do Paraná, com ênfase em Bromeliaceae e Orchidaceae (Processo 562248/2010-2).

\section{Referências}

Faria, A.P.G.; Wendt, T. \& Brown, G.K. 2010. A revision of Aechmea subgenus Macrochordion (Bromeliaceae) based on phenetic analyses of morphological variation. Botanical Journal of the Linnean Society 162: 1-27.

Fidalgo, O. \& Bononi, V.L.R. 1984. Técnicas de coleta, preservação e herborização de material botânico. Instituto de Botânica, São Paulo. 62p.

Forzza, R.C.; Costa, A.; Siqueira-Filho, J.A.; Martinelli, G.; Monteiro, R.F.; Santos-Silva, F.; Saraiva, D.P. \& Paixão-Souza, B. 2013. Bromeliaceae. In: Forzza et al. (eds.). Lista de espécies da flora do Brasil. Instituto de Pesquisas Jardim Botânico, Rio de Janeiro. Disponível em $<$ http://floradobrasil.jbrj. gov.br/jabot/floradobrasil/FB5818>. Acesso em 7 Mai 2013.
Gonçalves, E.G. \& Lorenzi, H. 2011. Morfologia vegetal: organografia e dicionário ilustrado de morfologia das plantas vasculares. $2^{\text {a }}$ ed. Instituto Plantarum de Estudos da Flora, São Paulo. 544p.

Luther, H.E. 2008. An alphabetical list of bromeliad binomials. $11^{\text {th }}$ ed. The Bromeliad Society International. The Marie Selby Botanical Gardens, Sarasota. 113p. Disponível em $<$ http://www.selby. org/sites/all/files/Bromeliad_Binomial_List_For_ Web.pdf $>$. Acesso em 20 Ago 2012.

IUCN. 2001. International Union for Conservation of Nature. Red List Categories and Criteria: version 3.1. IUCN Species Survival Commission. IUCN, Gland, Switzerland and Cambridge. 30p. Disponível em $<$ http://www.iucnredlist.org/static/categories criteria_3_1>. Acesso em 3 Set 2012.

IUCN. 2012. International Union for Conservation of Nature. Guidelines for Application of IUCN Red List Criteria at Regional and National Levels: version 4.0. Gland, Switzerland and Cambridge. 41p. Disponível em < http://www.iucn.org/about/ work/programmes/species/our_work/the_iucn_red_ list/resources/guidelines_application/>. Acesso em 5 Mai 2013.

Pereira, E. 1972. Species Novae in Brasilia Bromeliacearum: Aechmea guaratubensis. Bradea. Boletim do Herbário Bradeanum 1: 278-279.

Radford, A.E.; Dickson, W.C.; Massey, J.R. \& Bell, C.R. 1974. Vascular plant systematics. Harper \& Row, New York. 891p.

Reitz, R. 1983. Bromeliáceas e a malária-bromélia endêmica. In: Reitz, R. (ed.). Flora ilustrada catarinense. Herbário Barbosa Rodrigues, Itajaí. $808 \mathrm{p}$.

Roderjan, C.V.; Galvão, F.; Kunyoshi, Y.S. \& Hatschbach, G.G. 2002. As unidades fitogeográficas do estado do Paraná. Ciência \& Ambiente 24: 75-92.

Ruiz, H. \& Pavon, J. 1797. Florae Peruvianae et Chilensis. Tipographio Plenariano, Roma. 149p.

Smith, L.B. 1955. The Bromeliaceae of Brazil. Smithsonian Miscellaneous Collections 126: 1-290.

Smith, L.B. \& Downs, R.J. 1979. Bromelioideae (Bromeliaceae). Flora Neotropica Monograph 14: 1493-2141.

Thiers, B. [continuously updated]. Index Herbariorum: a global directory of public herbaria and associated staff. New York Botanical Garden's Virtual Herbarium. Disponível em $<$ http://sweetgum.nybg. org/ih/>. Acesso em 7 Mai 2013.

Wanderley, M.G.L. \& Martins, S.E. 2007. Bromeliaceae. In: Wanderley, M.G.L.; Shepherd, G.J. \& Giulietti, A.M. (eds.). Flora fanerogâmica do estado de São Paulo. Instituto de Botânica, São Paulo. Vol 3. Pp. 39-161. 